\title{
CHANGES IN ANTIBIOTIC SUSCEPTIBILITY PATTERN OF ATYPICAL STAPHYLOCOCCUS AUREUS STRAINS ISOLATED FROM COWS OF THE SAME HERD IN 2008-2010
}

\author{
MAGDALENA MAŁKIŃSKA-HORODYSKA, JOANNA KUBIAK, HENRYKA LASSA, \\ AND EDWARD MALINOWSKI \\ Department of Pathophysiology of Reproduction and Mammary Gland, \\ National Veterinary Research Institute, 85-090 Bydgoszcz, Poland \\ magda.malkinska@piwet.pulawy.pl
}

Received: March 14, 2012

Accepted: May 22, 2012

\begin{abstract}
The isolates of Staphylococcus aureus strains were examined phenotypically by cultural features, tube coagulase test and clumping factor (CF), and genotypically by conventional PCR. The strains had positive reaction in CF test, but were negative in tube coagulase test. The analysed strains from the same cows in each year expressed also nuc and coa genes. About $25 \%$ of the strains were examined by the disc diffusion method for their sensitivity to antibiotics. During three years, the strains were highly susceptible in vitro to amoxicillin with clavulanic acid, oxacillin, bacitracin, and cefoperazone (more than 90\%), and highly resistant to tetracycline, neomycin, and streptomycin. Forty randomly chosen strains, and eight strains from the same cows in each year were analysed for minimal inhibitory concentration of penicillin $\mathrm{G}$ using microdilution method. An increasing resistance to the penicillin was noted. Moreover, eight strains, the same in each year, were also examined for $\beta$-lactamase production and methicillin resistance. No $\beta$-lactamase producers and no methicillin resistant strains were found using phenotypic and genotypic methods. In conclusion, it can be stated that antimicrobial susceptibility can change from one year to another.
\end{abstract}

Key words: cows, mastitis, atypical Staphylococcus aureus, antibiotic susceptibility.

Staphylococcus aureus is considered to be a major pathogen that causes intramammary infections in dairy cows leading to severe economic losses in dairy industry (9). One of the typical features that distinguishes the more pathogenic Staphylococcus aureus strains from the less pathogenic staphylococci is the ability to produce coagulase $(2,6)$. Coagulase is an enzyme, which coagulates plasma and occurs in two forms: free and bound. Free coagulase (tube-coagulase) is produced extracellularly and acts on fibrinogen converting it to fibrin, which results in plasma clotting. Bound coagulase is an enzyme, which binds with cell's wall, acting directly on fibrinogen, and is detected in slide coagulase test $(20,21)$. The tube-coagulase test (TCT) is still the 'gold standard' in clinical microbiology laboratory (1). S. aureus is generally coagulase-positive although atypical coagulase-negative strains also occur (5).

It is important to determinate antimicrobial susceptibility of $S$. aureus strains not only for the purpose of therapy, but also to monitor the spread of resistant strains throughout the populations (4). Antimicrobial therapy plays a role in mastitis control by reducing the levels of herd infections and by preventing new infections (33). However, antibiotic treatment of mastitis leads to significant increase in milk quantity and quality, lower somatic cell count, and is likely associated with reduction in prevalence of clinical mastitis among herds, which is economically beneficial (25).

The efficacy of bovine mastitis treatment depends on the cause, clinical manifestation, antibiotic susceptibility of aetiological agents, and the efficiency of immunological system (18). However, cure rates of $S$. aureus infections are poor after antibiotic treatment mainly because of resistance of the bacteria $(11,18)$ and capsule and slime formation (30). Therapy of $S$. aureus infections is usually made empirically and is often based on previous susceptibility information for the herd. Thus, information on susceptibility trends for bacterial species within a given herd is extremely important (26).

Atypical staphylococci, causing problems in the production of milk of acceptable quality, were the main reason of intramammary infections in the farm in 20082010. In the treatment of mastitis, the most often used drugs were those containing $\beta$-lactamic antibiotics, especially penicillin $\mathrm{G}$ and its half-synthetic derivatives. Because of this fact, the aim of the presented study was to characterise changes in susceptibility pattern of atypical $S$. aureus strains to antibiotics, especially penicillin $\mathrm{G}$, in the examined herd. 


\section{Material and Methods}

Bacterial isolates. The examined staphylococci were isolated from milk samples of cows belonging to the same herd. The samples were collected from 468 cows in 2008, 526 cows in 2009, and 314 cows in 2010, but because of a high culling rate in the herd during this time, only eight cows were the same in each year. Samples were collected, cooled, and transported to the laboratory, as described earlier (19). Bacteriological examinations were performed according to the commonly accepted rules (17).

Genetic examination. Strains from eight cows, the same in each year, were examined for nuc, coa, $m e c A$, and blaZ genes by conventional PCR.

Antibiotic susceptibility. The antimicrobial sensitivity of $25 \%$ of the isolates from each year, was tested by the disc diffusion method in the MuellerHinton agar (Oxoid). The following discs with antibacterial agents (Oxoid) were used: amoxicillin with clavulanic acid $(30 \mu \mathrm{g})$, penicillin $\mathrm{G}$ (10 i.u.); cephalexin (30 $\mu \mathrm{g})$, cloxacillin (5 $\mu \mathrm{g})$, bacitracin (10 i.u.), cefoperazone $(30 \mu \mathrm{g})$, tetracycline $(30 \mu \mathrm{g})$, neomycin $(30 \mu \mathrm{g})$, streptomycin $(10 \mu \mathrm{g})$, and oxacillin $(1 \mu \mathrm{g})$. In case of eight strains, the same during three years, antimicrobial sensitivity to penicillin $G$ (10 i.u.) and cefoxitin (30 i.u; Oxoid) were tested by the disc diffusion method in the Mueller-Hinton agar (Oxoid). The interpretation of the test results: sensitive (S), resistant (R), was based on Clinical and Laboratory Standards Institute (CLSI) criteria (3).
Minimal inhibitory concentration (MIC). On 40 randomly chosen strains, the MICs of penicillin G was determined by the broth microdilution method as described in CLSI criteria (3). On eight strains from the same cows in each year, the MICs of penicillin G, oxacillin, and cefoxitin were determined by the broth microdilution method. Reference strains, $S$. aureus ATCC 29213 and Escherichia coli ATCC 25922, were used for quality control. The susceptibility of each strain to antimicrobial agents was then defined by comparing the results to those of the breakpoint values. The first dilution with no visible growth was considered as MIC for each isolate.

$\boldsymbol{\beta}$-lactamase production. Eight strains from each year were analysed for $\beta$-lactamase production using nitrocefin sticks according to manufacturer's recommendation (Oxoid).

\section{Results}

Atypical S. aureus strains were isolated from 264 cows in 2008, from 244 cows in 2009, and from 184 cows in 2010 that comprised $56.4 \%, 46.4 \%$, and $58.6 \%$ of all cows in the herd, respectively. Apart from these bacteria, infections were also caused by free coagulasepositive $S$. aureus strains, free coagulase-negative staphylococci (non-haemolytic, free coagulase-negative, and clumping factor-negative), Streptococcus sp., coliform bacteria, and Corynebacterium sp. (Table 1).

Table 1

Proportional participation of microorganisms in the same herd in 2008-2010

\begin{tabular}{lccc}
\hline \multicolumn{1}{c}{ Microorganism } & $2008(\%)$ & $2009(\%)$ & $2010(\%)$ \\
\hline S. aureus (free coagulase negative) & 26.6 & 21.4 & 58.6 \\
\hline S. aureus (free coagulase positive) & 0.1 & 0.1 & 0.0 \\
\hline CNS & 18.8 & 8.1 & 23.9 \\
\hline Streptococcus sp. & 0.8 & 1.5 & 1.0 \\
\hline Coliform bacteria & 0.3 & 0.5 & 0.6 \\
\hline Coryneform bacteria & 0.1 & 0.2 & 0.0 \\
\hline Bacteriologically negative samples & 51.0 & 67.5 & 15.6 \\
\hline Contaminated samples & 2.3 & 0.7 & 0.3 \\
\hline
\end{tabular}

Table 2

Minimal inhibitory concentration (MIC) for penicillin G of 40 strains of atypical S. aureus isolated from cows of the same herd in 2008-2010

\begin{tabular}{|c|c|c|c|c|c|c|}
\hline & \multirow{2}{*}{$\begin{array}{c}\mathrm{MIC}(\mu \mathrm{g} / \mathrm{mL}) \\
\text { breakpoints }\end{array}$} & \multirow{2}{*}{$\begin{array}{l}\text { Range } \\
(\mu \mathrm{g} / \mathrm{mL})\end{array}$} & \multicolumn{2}{|c|}{ Susceptible } & \multicolumn{2}{|c|}{ Resistant } \\
\hline & & & $\mathrm{n}$ & $\%$ & $\mathrm{n}$ & $\%$ \\
\hline 2008 & \multirow{3}{*}{$\begin{array}{l}\leq 0.12 \\
\geq 0.25\end{array}$} & $0.03-0.25$ & 39 & $97.5 \%$ & 1 & $2.5 \%$ \\
\hline 2009 & & $0.03-0.5$ & 34 & $85 \%$ & 6 & $15 \%$ \\
\hline 2010 & & $0.12-0.5$ & 22 & $55 \%$ & 18 & $45 \%$ \\
\hline
\end{tabular}


Table 3

Minimal inhibitory concentration (MIC) for penicillin G, oxacillin, and cefoxitin of atypical S.aureus strains isolated from the same cows of the same herd in 2008-2010

\begin{tabular}{|c|c|c|c|c|c|c|c|c|c|c|}
\hline \multirow{2}{*}{ Antibiotic } & \multirow{2}{*}{$\begin{array}{c}\text { MIC } \\
\text { breakpoints } \\
(\mu \mathrm{g} / \mathrm{mL})\end{array}$} & \multicolumn{3}{|c|}{ Range $(\mu \mathrm{g} / \mathrm{mL})$} & \multicolumn{3}{|c|}{ Susceptible (\%) } & \multicolumn{3}{|c|}{ Resistant (\%) } \\
\hline & & 2008 & 2009 & 2010 & 2008 & 2009 & 2010 & 2008 & 2009 & 2010 \\
\hline Penicillin & $\begin{array}{l}\leq 0.12 \\
\geq 0.25\end{array}$ & $\begin{array}{l}0.015- \\
0.12\end{array}$ & $\begin{array}{l}0.03- \\
0.25\end{array}$ & $\begin{array}{c}0.03- \\
1.0\end{array}$ & 100 & 87.5 & 62.5 & 0 & 12.5 & 37.5 \\
\hline Oxacillin & $\begin{array}{l}\leq 2 \\
\geq 4\end{array}$ & $\begin{array}{c}0.25- \\
1.0\end{array}$ & $\begin{array}{c}0.5- \\
1.0\end{array}$ & $\begin{array}{c}0.5- \\
1.0\end{array}$ & 100 & 100 & 100 & 0 & 0 & 0 \\
\hline Cefoxitin & $\begin{array}{l}\leq 4 \\
\geq 8\end{array}$ & $\begin{array}{l}1.0- \\
2.0\end{array}$ & $\begin{array}{l}1.0- \\
4.0\end{array}$ & $\begin{array}{c}2.0- \\
4.0\end{array}$ & 100 & 100 & 100 & 0 & 0 & 0 \\
\hline
\end{tabular}

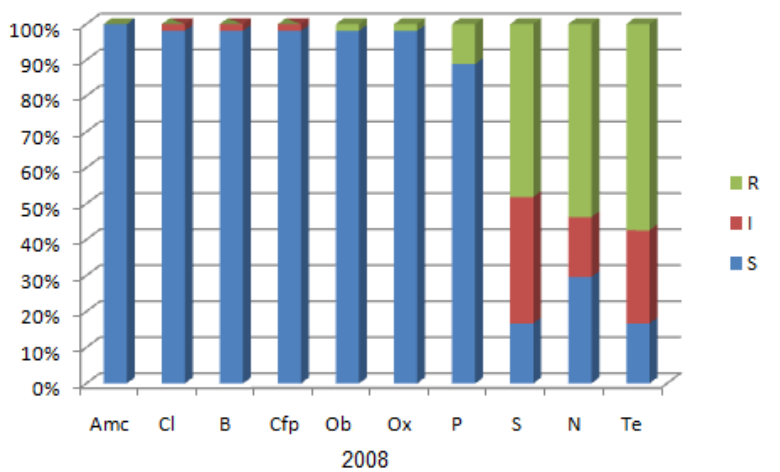

Fig. 1. Sensitivity to antibiotics of atypical S. aureus isolated from cows with mastitis in 2008;

S - sensitive, I - intermediate sensitive, R - resistant; Amc amoxicillin with clavulanic acid, $\mathrm{Cl}$ - cephalexin, B bacitracin, $\mathrm{Cfp}$ - cefaperazone, $\mathrm{Ob}$ - cloxacillin, $\mathrm{Ox}$ oxacillin, $\mathrm{P}$ - penicillin, $\mathrm{S}$ - streptomycin, $\mathrm{N}$ - neomycin,

$\mathrm{Te}$ - tetracycline.

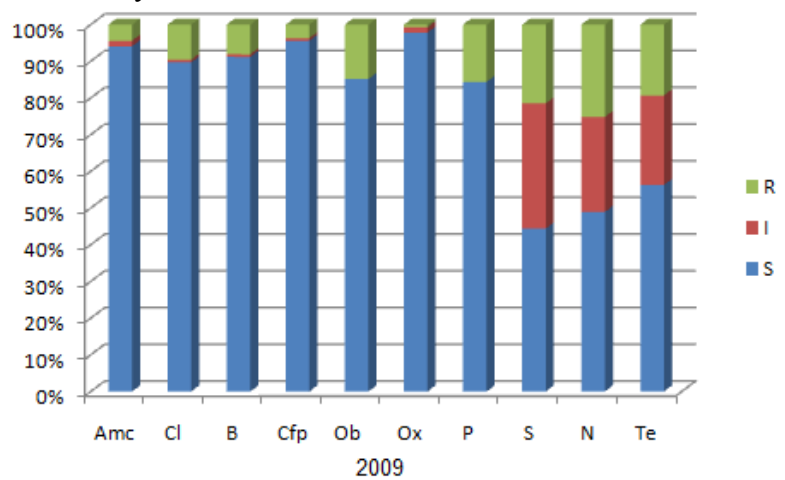

Fig. 2. Sensitivity to antibiotics of atypical $S$. aureus isolated from cows with mastitis in 2009; symbols as in Fig. 1.

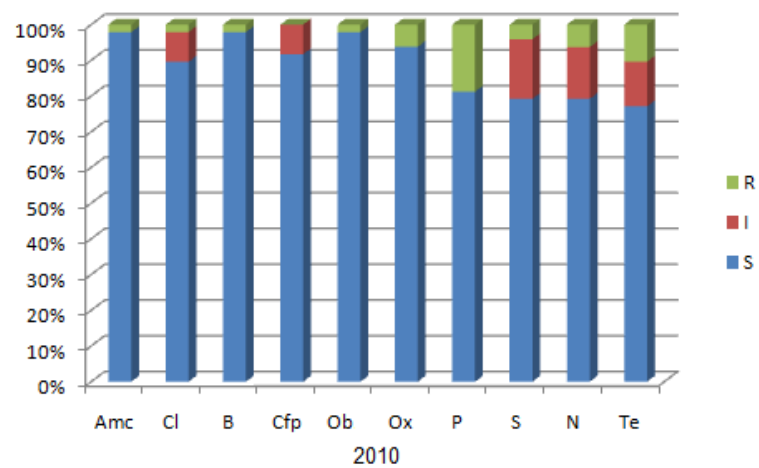

Fig. 3. Sensitivity to antibiotics of atypical $S$. aureus isolated from cows with mastitis in 2010; symbols as in Fig. 1.
The tested $S$. aureus strains gave positive results in the slide coagulase test, but the tube coagulase test was negative. Eight strains from the same cows in 2008-2010 expressed also the nuc and coa genes but none of them expressed mecA and blaZ genes.

All analysed strains in 2008 (Fig. 1) were especially in vitro sensitive to amoxicillin with clavulanic acid (100\%), cephalexin (98.1\%), bacitracin (98.1\%), cefoperazone $(98.1 \%)$, cloxacillin $(98.1 \%)$, and oxacillin $(98.1 \%)$, and mostly resistant to tetracycline (57.4\%), neomycin (53.7\%), and streptomycin (48.1\%); in 2009 (Fig. 2) among the most active antibiotics against the strains were: oxacillin $(97.8 \%)$, cefoperazone (95.6\%), and amoxicillin with clavulanic acid (94.1\%), and less active included: neomycin (25.2\%), streptomycin $(21.5 \%)$, and tetracycline $(19.3 \%)$; in 2010 (Fig. 3) the highest effectiveness had amoxicillin with clavulanic acid, bacitracin, and cloxacillin (97.9\%), and clearly lower effectiveness had penicillin G (18.7\%), tetracycline $(10.4 \%)$, and neomycin $(6.3 \%)$.

However, eight strains isolated from the same cows in each year were sensitive to penicillin G in $100 \%$ in 2008 , in $75 \%$ in 2009 , and in $50 \%$ in 2010 , and all strains were sensitive to cefoxitin.

Control strain value was within recommended ranges for microdilution method. During three years, higher number of resistant isolates was observed for penicillin G. In 2008 , only $2.5 \%$ of 40 randomly chosen strains were resistant to this antibiotic, while in 2009, the percentage of resistant strains increased to $15 \%$ and reach even $45 \%$ in 2010 (Table 2). In case of eight strains from the same cows, in 2008 all analysed strains were sensitive to penicillin $G$, while in 2009 , the percentage of resistant strains increased to $12.5 \%$ and reached $37.5 \%$ in 2010 (Table 3). In spite of increasing range of antibiotic dilution in time, resistance to oxacillin and cefoxitin was not observed.

By using identification sticks, no $\beta$-lactamase producers were found among eight strains of atypical $S$. aureus isolated in 2008-2010.

\section{Discussion}

All examined strains were coagulase-negative but clumping factor positive. The strains from the same cows in 2008-2010 expressed also nuc and coa genes, 
which are characteristic for $S$. aureus $(2,6)$. Because of these features, the analysed staphylococci can be called atypical $S$. aureus.

Atypical staphylococci, causing problems with the production of an acceptable quality of milk, were the main reason of intramammary infections at the farm. They were found in $27 \%$ in $2008,21 \%$ in 2009 , and $58.6 \%$ in 2010 of all examined quarter milk samples. Similar results were noted by Gooraninejad et al. (10), Jánosi and Baltay (12), and Kumar et al. (13) who found S. aureus in $26.4 \%, 32.5 \%$, and $54.9 \%$ milk samples, respectively.

Antimicrobial therapy is a primary tool for controlling staphylococcal mastitis. Antimicrobial susceptibility tests can guide the veterinarian in selecting the most appropriate antimicrobial agent for treatment of the disease caused by $S$. aureus (23). In fact, $S$. aureus pathogens have many characteristics that make them difficult targets for antimicrobial therapy (29). The previous studies regarding antibiotic resistance in $S$. aureus revealed that antibiotic resistance genes are often located on plasmids and transposons, which can easily pass from one staphylococcal species to another (15, $35)$.

Despite a variety of available antimicrobial agents, success in the treatment of $S$. aureus mastitis is still very low. In cases of mastitis, the incorrect or incomplete treatment of animals also contributes significantly to the development of bacterial resistance against antibiotics (31). The reason of decreasing sensitivity to antibiotics can be also the frequency of treatment in the analysed region, because frequent contact of bacteria with a specific antibiotic can determine an increase in resistance and decrease the effect of treatment (16). The indiscriminate use of antibiotics for the treatment of cows has led to development of multiple antibiotic resistant strains thereby rendering the antibiotic treatment ineffective (35). Some authors $(7,16)$ reported that in vitro antibiotic resistance of bacteria isolated in the same farm can change from one year to another. The statement was confirmed in our research where resistance to penicillin $\mathrm{G}$, which was the most often used in antibiotic treatment in that herd, was higher in disc diffusion method as well as in microdilution method every year. In disc diffusion method, the resistance to penicillin $\mathrm{G}$ of randomly chosen strains increased from $11.1 \%$ in 2008 to $18.7 \%$ in 2010 and even more in case of eight strains from the same cows repeated in each year, where resistance to penicillin $\mathrm{G}$ increased from $0 \%$ to $50 \%$ during the time of experiment. Our findings are in agreement with the result obtained by Gooraninejad et al. (10), who reported that $57.4 \%$ of $S$. aureus isolates were resistant to penicillin $\mathrm{G}$.

Moreover, in microdilution method, the number of resistant strains and range of resistance to penicillin $G$ increased each year. In case of randomly chosen strains, proportional distribution of resistant strains increased from $2.5 \%$ in 2008 to $45 \%$ in 2010 , and in case of eight strains from the same cows in each year, distribution of resistant strains increased from $0 \%$ in 2008 to $37.5 \%$ in 2010. In this study, the MIC varied from 0.015 to 1.0 $\mu \mathrm{g} / \mathrm{mL}$. Ünal et al. (32) and Russi et al. (27) noted $80.4 \%$ and $48.4 \%$ of $S$. aureus strains resistant to penicillin $G$ in microdilution method, respectively. The range of minimal concentration of antibiotic, which stops growth of bacteria, differs among countries, for example: from 0.06 to $0.5 \mu \mathrm{g} / \mathrm{mL}$ in Norway (24), from 0.06 to $1.0 \mu \mathrm{g} / \mathrm{mL}$ in Denmark (28), and to $8.0,16.0$, and $64.0 \mu \mathrm{g} / \mathrm{mL}$ in the United States, Germany, or New Zealand, respectively $(24,28)$.

The $\beta$-lactams remain one of the most widely used classes of antimicrobial agents for treatment of bovine mastitis. Bacterial resistance mechanisms to this class of antibiotics include production of B-lactamases encoded by blaZ gene and low-affinity penicillinbinding protein $2 \mathrm{a}(\mathrm{PBP} 2 \mathrm{a})$ determined by the presence of the chromosomal gene mecA (22). The detection of $\beta$ lactamase production in staphylococci is a useful and rapid method to detect penicillin resistance. Test for $\beta$ lactamase production should always be done to obtain the true picture of resistance to penicillin in staphylococci (8). In this research, among the same strains tested in 2008-2010, no $\beta$-lactamase producers were found using phenotypic (identification sticks) and genotypic (expression of blaZ gene) methods.

Strains expressing the mecA gene are referred to as methicillin resistant. Watts and Salmon (34) have emphasised the need to identify methicillin-resistant Staphylococcus aureus (MRSA) because these strains are resistant to all compounds currently approved for the treatment of bovine mastitis. Diagnosis of methicillin resistance in laboratory is based on the testing of oxacillin, where according to recommendations of the CLSI, oxacillin-resistant Staphylococcus isolates should be reported as resistant to other $\beta$-lactam antibiotics (3). In addition, the CLSI also recommends a cefoxitin disc diffusion test for the prediction of mecA-mediated resistance in staphylococci (3). In veterinary medicine, methicillin-resistant $S$. aureus strains are reported occasionally (14). Atypical S. aureus did not express the $m e c A$ gene, and all strains were sensitive to oxacillin in microdilution, as well to cefoxitin in both disc diffusion and microdilution methods.

The presented study demonstrated the existence of progressive level of resistance of $S$. aureus strains to commonly used antimicrobial agent in the studied farm. Therefore, to avoid the selection of resistant strains, it is very important to make a systematic application of an in vitro antibiotic susceptibility tests prior to the use of antibiotics in both treatment and prevention of intramammary infections.

\section{References}

1. Bannerman T.L.: Staphylococcus, Micrococcus, and other catalase-positive cocci that grow aerobically. Manual of clinical microbiology. ASM Press, Washington DC, 2003.

2. Cabral da Silva Santos O., Mdenezes Barros E., Vasconcelos Paida Brito M.A., do Carmo de Freire Bastos M., Netto dos Santos K.R., Giambiagi-deMarval M.: Identification of coagulase-negative staphylococci 
from bovine mastitis using RFLP-PCR of the groEL gene. Vet Microbiol 2008, 130, 134-140.

3. Clinical and Laboratory Standards Institute. Performance Standards for Antimicrobial Disk and Dilution Susceptibility Tests for Bacteria Isolated from Animals. Approved Standard M31-A3. CLSI, Wayne, USA, 2008.

4. Coelho S.M.O., Reinoso E., Pereira I.A., Soares L.C., Demo M., Bogni C., Souza M.M.S.: Virulence factors and antimicrobial resistance of Staphylococcus aureus isolated from bovine mastitis in Rio de Janeiro. Pesq Vet Bras 2009, 29, 369-374.

5. Fox L.K., Beser T.E., Jackson S.M.: Evaluation of coagulase-negative variant of Staphylococcus aureus as a cause of intramammary infections in a herd of dairy cattle. J Am Vet Med Assoc 1996; 209, 1143-1146.

6. Garbacz K., Goliński J.: Atypical Staphylococcus aureus strains defective in coagulase or clumping factor (CF). Post Microbiol 2006, 45, 39-43.

7. Garrison L.L., Schukken Y.H., Hilton B.: Antibiotic susceptibility patterns for various bacterial intramammary pathogens over 15 years: results and analysis of a database. Proceedings of National Mastitis Council Annual Meeting. Atlanta, USA, 2000, pp. 215216.

8. Gianneechini R.E., Concha C., Franklin A.: Antimicrobial susceptibility of udder pathogens isolated from dairy herds in the west littoral region of Uruguay. Acta Vet Scand 2002, 43, 31-41.

9. Godden S.M., Jansen J.T., Leslie K.E., Smart N.L., Kelton D.F.: The effect of sampling time and sample handling on the detection of Staphylococcus aureus in milk from quarters with subclinical mastitis. Can Vet $\mathrm{J}$ 2002, 43, 38-42.

10. Gooraninejad S., Ghobanpoor M., Salati A.P.: Antibiotic susceptibility of staphylococci isolated from subclinical mastitis. Pak J Bio Sci 2007, 10, 2781-2783.

11. Gruet P., Maincent P., Berthelot X., Kaltsatos V.: Bovine mastitis and intramammary drug delivery: review and perspective. Adv Drug Deliv Rev 2001, 50, 245-259.

12. Jánosi S., Baltay Z.: Correlations among the somatic cell count of individual bulk milk, result of the California mastitis test and bacteriological status of the udder in dairy cows. Acta Vet Hung 2004, 52, 173-183.

13. Kumar R., Yadav B.R., Singh R.S.: Antibiotic resistance and pathogenicity factors in Staphylococcus aureus isolated from mastitic Sahiwal cattle. J Biosci 2011, 36, 175-188.

14. Lee J.H.: Methicillin (oxacillin) - resistant Staphylococcus aureus strains isolated from major food animals and their potential transmission to humans. Appl Environ Microbiol 2003, 69, 6489-6494.

15. Lyon B.R., Skurray R.: Antimicrobial resistance of Staphylococcus aureus: genetic basis. Microbiol Rev 1987, 51, 88-134.

16. Malinowski E., Pilaszek J., Kłossowska A., Sobolewska S., Sobolewski J.: Changes in susceptibility to antibiotics in bacteria isolated from clinical manifestations of mastitis in cows in the years 1987-1996. Medycyna Wet 1997, 53, 722-725.

17. Malinowski E., Kłossowska A.: Diagnostyka zakażeń i zapaleń gruczołu mlekowego krów. Published by PIWet, Pulawy, Poland, 2002.

18. Malinowski E., Kłossowska A., Kaczmarowski M., Lassa H., Kuźma K.: Antimicrobial susceptibility of staphylococci isolated from affected with mastitis cows. Bull Vet Inst Pulawy 2002, 46, 289-294.

19. Malinowski E, Lassa H., Kłossowska A., Smulski S., Kaczmarowski M.: Atypical Staphylococcus aureus as an aetiological agent of mastitis in cows. Bull Vet Inst Pulawy 2009, 53, 383-387.

20. McDevitt D., Vaudaux P., Foster T.J.: Genetic evidence that bound coagulase of Staphylococcus aureus is not clumping factor. Infect Immun 1992, 60, 1514-1523.

21. McDevitt D., Francois P., Vaudaux P., Foster T.J.: Molecular characterization of the clumping factor (fibrinogen receptor) of Staphylococcus aureus. Mol Microbiol 1994, 11, 237-248.

22. Moon J.S., Lee A.R., Kang H.M., Lee E.S., Kim M.N., Paik Y.H., Park Y.H., Joo Y.S., Koo H.S.: Phenotypic and genetic antibiogram of methicillin-resistant staphylococci isolated from bovine mastitis in Korea. J Dairy Sci 2007, 90, 1176-1185.

23. Moroni P., Pisoni G., Antonini M., Villa R., Boettcher P., Carli S.: Short communication: antimicrobial drug susceptibility of Staphylococcus aureus from subclinical bovine mastitis in Italy. J Dairy Sci 2006, 89, 29732976.

24. Oliveira A.P. de, Watts J.L., Salmon S.A., Aerestrup F.M.: Antimicrobial susceptibility of Staphylococcus aureus isolated from bovine mastitis in Europe and in the United States. J Dairy Sci 2000, 83, 855-862.

25. Oliver S.P., Lewis M.J., Gillespie B.E., Dowlen H.H., Jaenicke E.C., Roberts R.K.: Prepartum antibiotic treatment of heifers: milk production, milk quality and economic benefit. J Dairy Sci 2003, 86, 1187-1193.

26. Owens W.E., Ray C.H., Watts J.L., Yancey R.J.: Comparison of success of antibiotic therapy during lactation and results of antimicrobial susceptibility tests for bovine mastitis. J Dairy Sci 1997, 80, 313-317.

27. Russi N.B., Bantar C., Calvinho L.F.: Antimicrobial susceptibility of Staphylococcus aureus causing bovine mastitis in Argentine dairy herds. Rev Argentina Microbiol 2008, 40, 116-119.

28. Salmon S.A., Watts J.L., Aarestrup F.M., Pankey J.W., Yancey R.J.: Minimum inhibitory concentrations for selected antimicrobial agents against organisms isolated from the mammary glands of dairy heifers in New Zealand and Denmark. J Dairy Sci 1998, 81, 570-578.

29. Sol J., Sampimon O.C., Barkema H.W., Schukken Y.H.: Factors associated with cure after therapy of clinical mastitis caused by Staphylococcus aureus. J Dairy Sci 2000, 83, 278-284.

30. Sutra L., Poutrel B.: Virulence factors involved in the pathogenesis of bovine intramammary infections due to Staphylococcus aureus. J Med Microbiol 1994, 40, 79.

31. Turutoglu H., Ercelik S., Ozturk D.: Antibiotic resistance of Staphylococcus aureus and coagulase-negative staphylococci isolated from bovine mastitis. Bull Vet Inst Pulawy 2006, 50, 41-45.

32. Ünal N., Istanbulluoğlu E., Gür D., Ünal S., Bulun H.: Genetic variation and antibiotic resistance patterns of Staphylococcus aureus isolates from human and bovine. Rev Méd Vét 2009, 10, 463-468.

33. Unakal C.G., Kaliwal B.B.: Prevalence and antibiotic susceptibility of Staphylococcus aureus from bovine mastitis. Vet World 2010, 3, 65-67.

34. Watts J.R., Salmon J.A.: Activity of selected antimicrobial agents against strains of Staphylococcus aureus isolated from bovine intramammary infections that produce $\beta$-lactamase. J Dairy Sci 1997, 80, 788-791.

35. Werckenthin C., Cardoso M., Martel J.L., Schwarz S.: Antimicrobial resistance in staphylococci from animals with particular reference to bovine Staphylococcus aureus, porcine Staphylococcus hyicus, and canine Staphylococcus intermedius. Vet Res 2001, 32, 341-362. 